\title{
Case Report \\ Double Orifice Mitral Valve and Bicuspid Aortic Valve: Pieces of the Same Single Puzzle?
}

\author{
Faysal Şaylık, ${ }^{1}$ Ferit Onur Mutluer, ${ }^{1}$ Aydın Tosu, ${ }^{2}$ and Murat Selçuk ${ }^{1}$ \\ ${ }^{1}$ Department of Cardiology, Van Region Training and Research Hospital, 65300 Van, Turkey \\ ${ }^{2}$ Kanuni Sultan Süleyman Training and Research Hospital, 34303 Istanbul, Turkey \\ Correspondence should be addressed to Ferit Onur Mutluer; onurmd@gmail.com
}

Received 2 January 2015; Revised 26 March 2015; Accepted 26 March 2015

Academic Editor: Assad Movahed

Copyright (C) 2015 Faysal Şaylık et al. This is an open access article distributed under the Creative Commons Attribution License, which permits unrestricted use, distribution, and reproduction in any medium, provided the original work is properly cited.

\begin{abstract}
Double orifice mitral valve is a very rare congenital abnormality. Well known associations of this pathology with other congenital lesions point to a complex and central pathophysiological mechanism leading to a sequence of pathologies. These associations have long been realized and arbitrarily defined as Shone complex. We would like to present a 21-year-old patient with double orifice mitral valve associated with bicuspid aortic valve, with a brief review of the literature on possible central mechanisms leading to different subsets of congenital abnormalities involving these two.
\end{abstract}

\section{Introduction}

Double orifice mitral valve is a very rare congenital abnormality [1]. The left atrium opens to the left ventricle via mitral valve orifice divided into two by a fibrous tissue. Isolated occurrence of this abnormality is an even rarer phenomenon. Well known associations of this pathology with other congenital lesions point to a complex and central pathophysiological mechanism leading to a sequence of pathologies. These associations have long been realized and arbitrarily defined as Shone complex. We would like to present a case with cooccurring double orifice mitral valve and bicuspid aortic valve, with the aim of drawing attention to possible underlying mechanisms.

\section{Case Report}

A 21-year-old man presented to our outpatient clinic with exercise-induced chest pain and palpitations. There was nothing remarkable in medical or family history. Questioning of the functional status revealed NYHA class III dyspnea. Vitals were normal. Levine 3/6 apical diastolic murmur was noted in auscultation. ECG, chest X-ray, and routine blood work yielded normal results.

Transthoracic echocardiography clearly showed the mitral valve with 2 separate orifices. The gradients with continuous wave (CW) Doppler demonstrated severe mitral stenosis (24 mmHG mean gradient), in apical four-chamber and parasternal short axis (PSSX) view (Figures 1(a)-1(b)). An accompanying bicuspid aortic valve (BAV) with fusion of the left and right coronary cusps with insignificant gradient was observed in basal PSSX view (maximal and mean gradients of 18 and $12 \mathrm{mmHg}$, resp.). Transesophageal echocardiography (TOE) was performed to clarify mitral and aortic valve anatomy. DOMV was clearly visualized in TOE, and the gradient over the left ventricular outflow tract was localized to the level of the valve (Figures 2(a) and 2(b)). Coarctation of aorta or other associated congenital abnormalities was not detected. The patient was referred for surgery.

\section{Discussion}

DOMV is a very rare abnormality in which there are two separate orifices with separate respective chordal and papillary structures. This abnormality was first reported in 1876 by Greenfield [2]. Banerjee et al. reported incidence of this rare abnormality to be $0.05 \%$ [1]. DOMV is found to be associated with transposition of the great arteries, atresia of the left ventricle outflow tract, single coronary artery [3], ostium primum defect $[4,5]$, ostium secundum defect, ventricular septal defect and hypoplastic left heart 


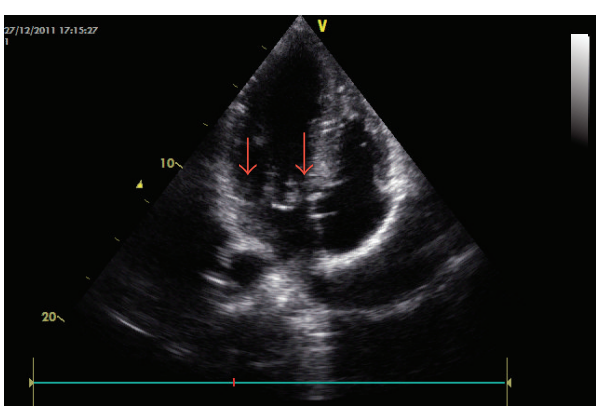

(a)

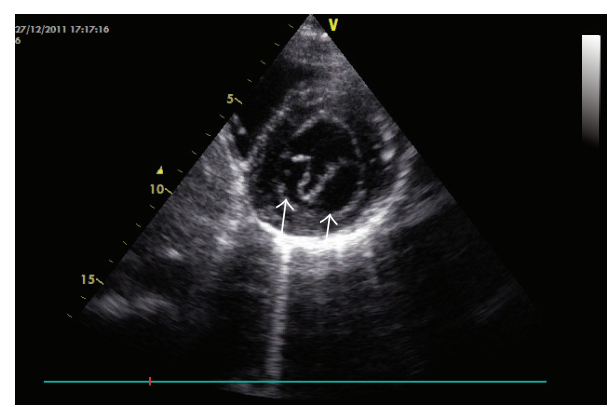

(b)

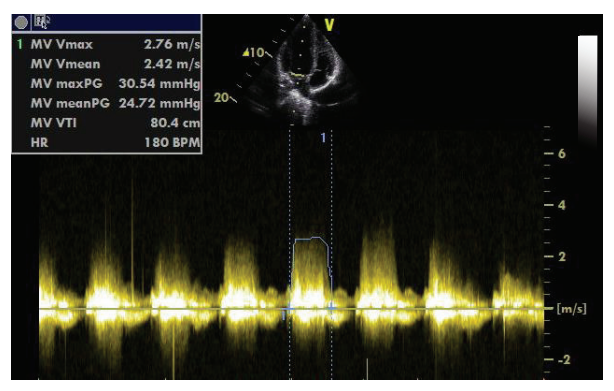

(c)

FIGURE 1: (a) Apical four-chamber view and (b) parasternal short axis view showing double orifice mitral valve. (c) Continuous wave Doppler tracings showing severe gradient over mitral valve.

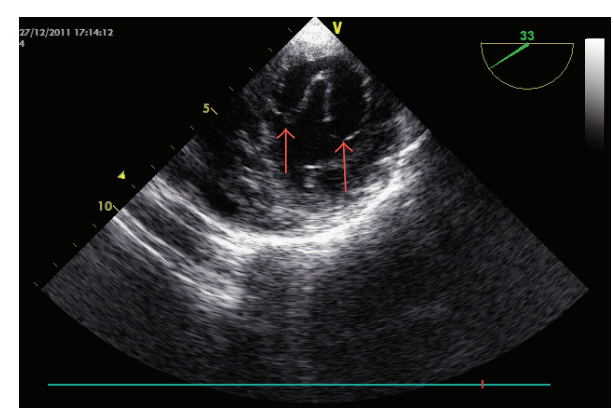

(a)

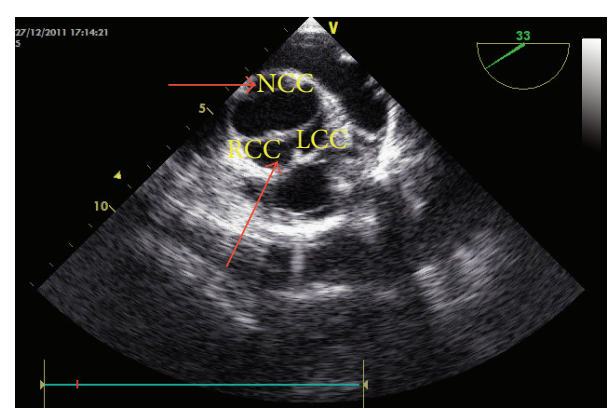

(b)

Figure 2: Modified section of mitral valve and short axis view of the bicuspid aortic valve with fusion of the left and right coronary cusps (LCC and RCC) in transesophageal echocardiography.

syndrome [5], persistent left superior vena cava, complete endocardial cushion defect [6], sinus venosus type ASD, Ebstein's abnormality and right atrial mass [7], left ventricular noncompaction [8], and cardiac papillary fibroelastoma [9] and as part of various syndromes with extracardiac and cardiac manifestations [10]. Isolated DOMV is very rare [11].

Valve development is a complex process which is not completely understood. Biomechanical properties of the valve and the surrounding as well as signalling pathways regulating migration and differentiation of cellular components of precursor are thought to be responsible for the embryogenesis and pathogenesis of subsequent valvular diseases.

Certain genes implicated in pathogenesis of BAV are found to regulate overall differentiation and morphogenesis of all the valves. For example, NOTCH-1 signalling, which is implicated in pathogenesis of aortic valve disease, is shown to play important roles in normal valvulogenesis of all the valves by regulating activity of various other genes and transcription factors. Abnormalities in this gene or other associated genes and/or transcription factors might be responsible for the pathogenesis of DOMV and other associated valvular abnormalities, vascular diseases, and congenital heart defects.

\section{Conclusion}

DOMV is a very rare lesion which might be associated with various other left sided obstructive lesions. The hypothesis that a central genetic abnormality may result in DOMV and other associated abnormalities is attractive and should be tested. In the clinical settings, patients with DOMV should undergo cautious and detailed assessment for other components of Shone complex. 


\section{Conflict of Interests}

The authors declare that there is no conflict of interests regarding the publication of this paper.

\section{References}

[1] A. Banerjee, T. Kohl, and N. H. Silverman, "Echocardiographic evaluation of congenital mitral valve anomalies in children," The American Journal of Cardiology, vol. 76, no. 17, pp. 1284-1291, 1995.

[2] W. S. Greenfield, "Double mitral valve," Transactions of the Pathological Society of London, vol. 27, pp. 128-129, 1876.

[3] J. E. Edwards, J. W. James, and S. J. Du, "Congenital malformation of the heart; origin of transposed great vessels from the right ventricle associated with atresia of the left ventricular outlet, double orifice of the mitral valve, and single coronary artery," Laboratory Investigation, vol. 1, no. 2, pp. 197-207, 1952.

[4] A. Mehrizi, G. M. Hutchins, and R. D. Roew, "Double orifice of the mitral valve: report of a case associated with ostium primum defect," Bulletin of the Johns Hopkins Hospital, vol. 117, pp. 8-15, 1965.

[5] E. Trowitzsch, A. Bano-Rodrigo, B. M. Burger, S. D. Colan, and S. P. Sanders, "Two-dimensional echocardiographic findings in double orifice mitral valve," Journal of the American College of Cardiology, vol. 6, no. 2, pp. 383-387, 1985.

[6] H. Watanabe, H. Miyamura, H. Kanazawa et al., "A surgical repair of complete endocardial cushion defect associated with single atrium, persistent left superior vena cava draining into the left atrium, hemiazygos connection and double orifice mitral valve," Kyobu Geka, vol. 45, no. 10, pp. 921-924, 1992.

[7] J. Narendra, S. V. Swamy, and C. Dhanalaxmi, "Double orifice mitral valve: report of 4 cases," The Journal of the Association of Physicians of India, vol. 40, no. 9, pp. 613-615, 1992.

[8] Ş. Gorgulu, S. Celik, A. Eksik, and T. Tezel, "Double-orifice mitral valve associated with nonisolated left ventricular noncompaction: a case report," Angiology, vol. 55, no. 6, pp. 707-710, 2004.

[9] N. Nwaejike and R. Ascione, "The competent isolated double orifice mitral valve: an incidental finding during excision of a papillary fibroelastoma," Annals of the Royal College of Surgeons of England, vol. 94, no. 5, pp. el82-183, 2012.

[10] T. Kamesui, M. Seki, M. Tsubota, M. Endo, S. Watanabe, and H. Sato, "A case of Ellis-van Creveld syndrome with partial atrioventricular septal defect and double orifice mitral valve," Nihon Kyobu Geka Gakkai Zasshi, vol. 45, no. 4, pp. 589-593, 1997.

[11] A. Agarwal, T. Kumar, S. Bhairappa, and N. C. Manjunath, "Isolated double-orifice mitral valve: an extremely rare and interesting anomaly," BMJ Case Reports, 2013. 


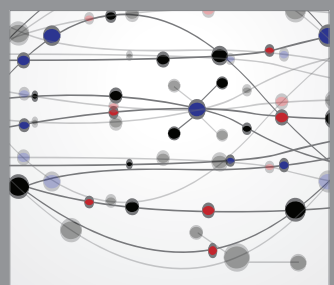

The Scientific World Journal
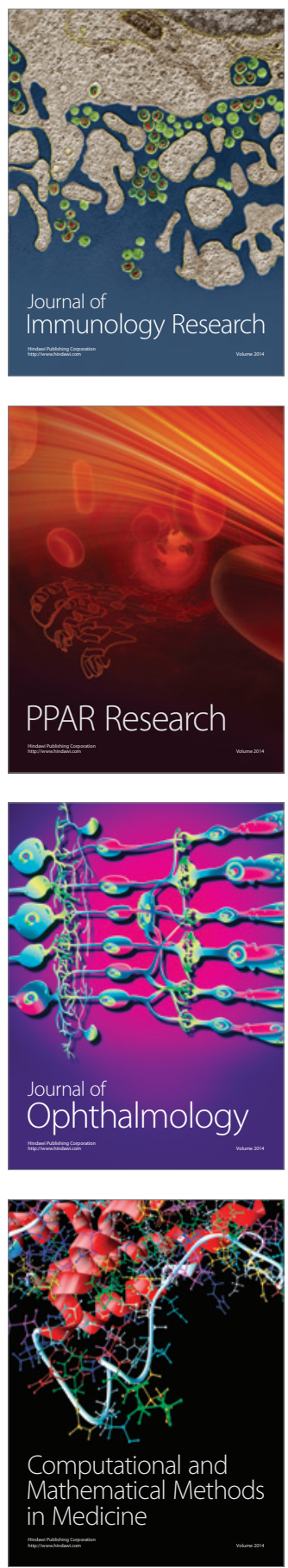

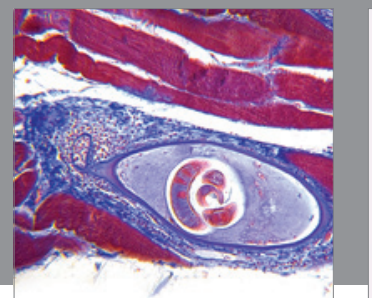

Gastroenterology

Research and Practice
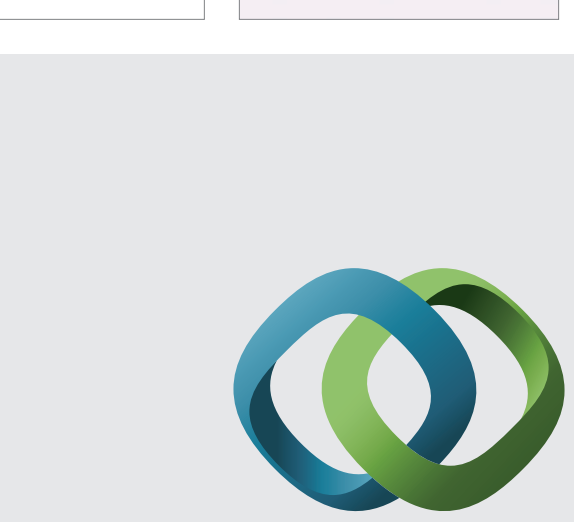

\section{Hindawi}

Submit your manuscripts at

http://www.hindawi.com
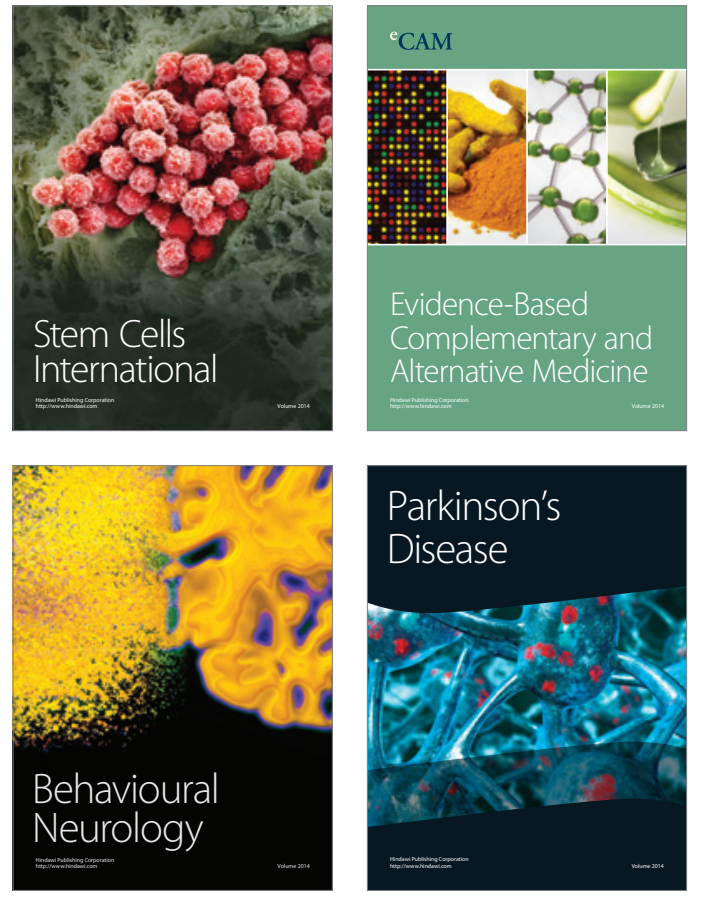
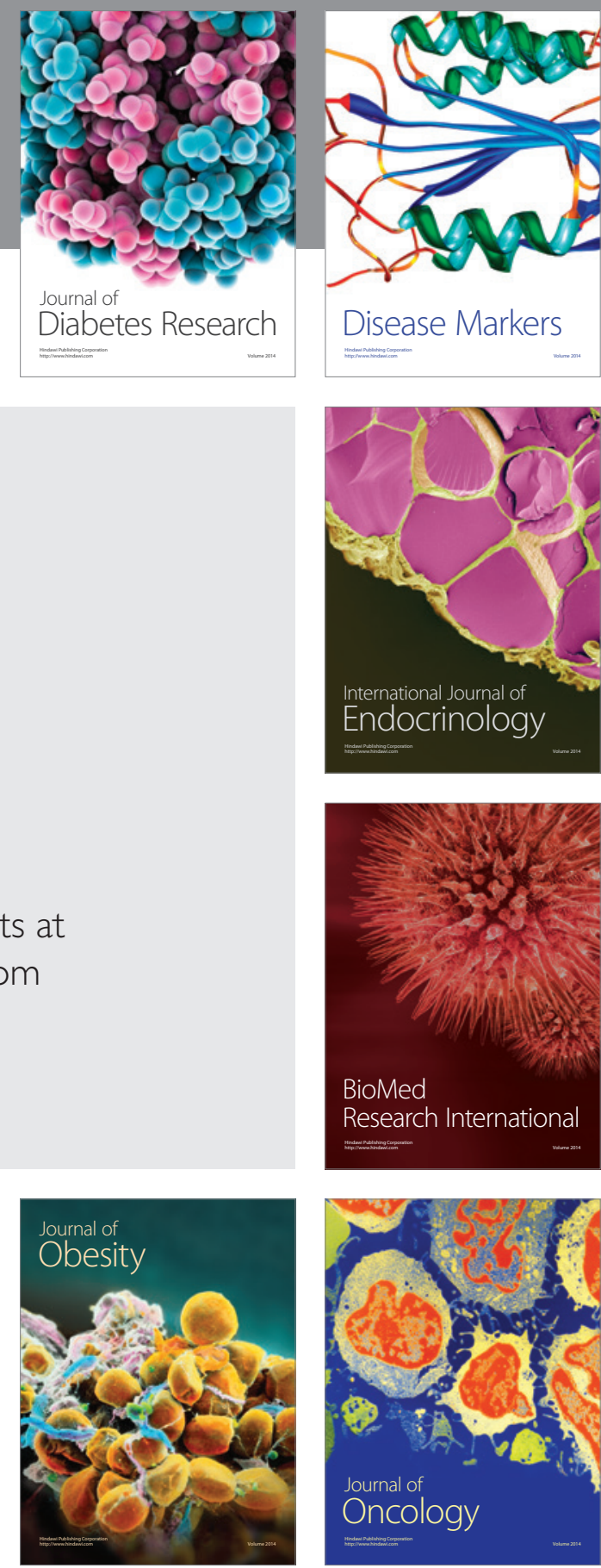

Disease Markers
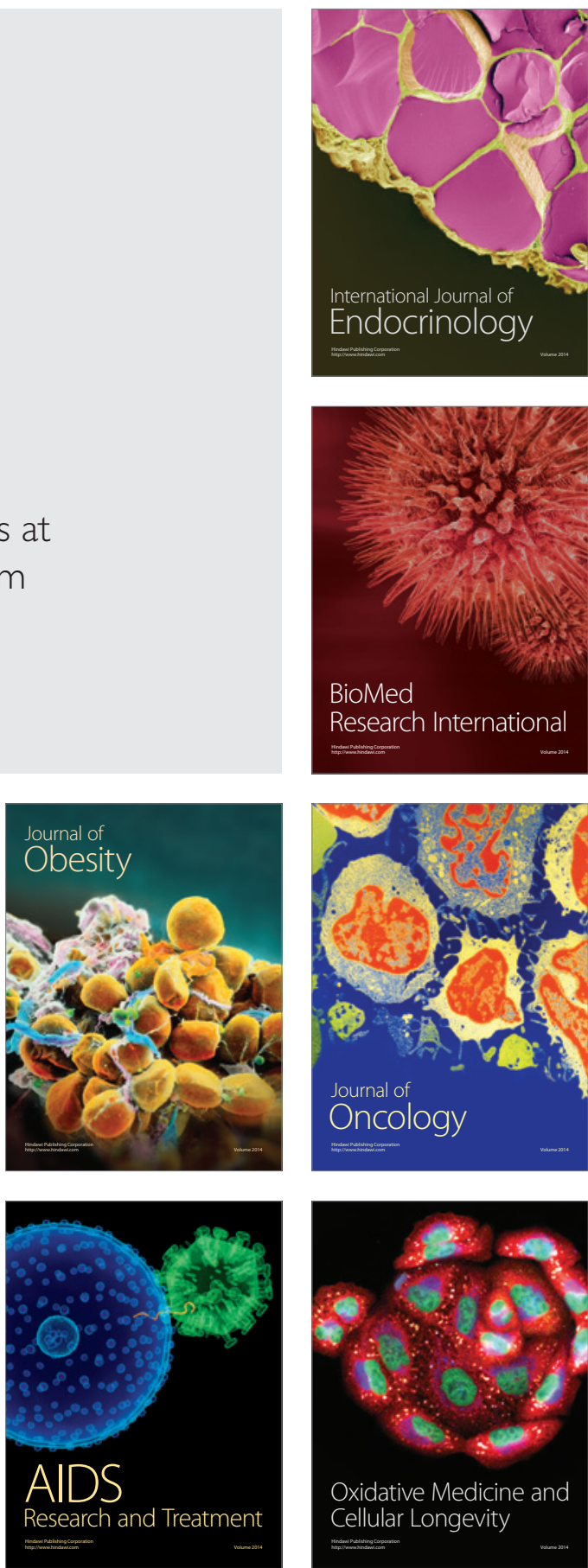